\title{
TRANSPORT PROJECT EVALUATION: FEASIBILITY RISK ASSESSMENT AND SCENARIO FORECASTING
}

\author{
Kim Bang Salling, Steen Leleur \\ Dept of Transport, Technical University of Denmark, Denmark
}

Submitted 26 August 2014; resubmitted 4 December 2014; accepted 9 January 2015; first published online 13 July 2015

\begin{abstract}
This paper presents a new approach to transport project assessment in terms of feasibility risk assessment and reference class forecasting. Conventionally, transport project assessment is based upon a Cost-Benefit Analysis (CBA) where evaluation criteria such as Benefit Cost Ratios (BCR) are obtained. Recent research has however proved that substantial inaccuracies are present when obtaining the monetary input to the CBA, particularly as concerns the construction costs and demand forecasts. This paper proposes a new approach in order to address these inaccuracies in a so-called Reference Scenario Forecasting (RSF) frame. The RSF is anchored in the cost-benefit analysis; thus, it provides decision-makers with a quantitative mean of assessing the transport infrastructure project. First, the RSF method introduces uncertainties within the CBA by applying Optimism Bias uplifts on the preliminary construction cost estimates. Hereafter, a quantitative risk analysis is provided making use of Monte Carlo simulation. This approach facilitates random input parameters based upon reference class forecasting, hence, a parameter data fit has been performed in order to obtain validated probability distribution functions. The latter have been placed and ultimately simulated on the inaccuracies of determining demand forecasts, i.e. leading to travel time savings and ticket revenues of the project. Finally, RSF makes use of scenario forecasting where trend scenarios such as economic growth and level of cross-border integration are investigated. The latter is highly relevant as RSF is demonstrated by a case example concerning the fixed link between Elsinore in Denmark and Helsingborg in Sweden.
\end{abstract}

Keywords: decision support systems; optimism bias; risk analysis; cost-benefit analysis; reference class forecasting; scenario analysis; UNITE-DSS model.

\section{Introduction}

This paper lays out a new approach to the assessment of transport infrastructure projects in terms of evaluating the embedded model uncertainties. Conventional transport infrastructure project assessments are based upon cost-benefit analyses in order to appraise whether the project is feasible or not in terms of Net Present Values (NPV), Benefit Cost Ratios (BCR), etc. Mackie, Preston (1998) points to 21 sources of uncertainties or biases in transport project appraisals particularly present in the use of conventional Cost-Benefit Analysis (CBA). Accordingly, recent research (e.g. Salling 2008; Salling, Banister 2009; Salling, Leleur 2011; Næss et al. 2012; Nicolaisen 2012) has proven that the point estimates derived from such analyses are embedded with a large degree of uncertainties. Thus, a new scheme has been introduced in terms of applying Quantitative Risk Analysis (QRA) and Monte Carlo simulation in order to represent the uncertainties within the CBA.
The QRA technique is therein supplemented with Reference Class Forecasting (RCF) depicting the historical tendency of overestimating transport related benefits (user demands i.e. travel time savings) and underestimating investment costs (Flyvbjerg et al. 2003; Flyvbjerg 2007; Odeck 2010; Cantarelli et al. 2010; Welde, Odeck 2011). RCF implies a compilation of past projects similar to the one being appraised in order to compare the deficiencies/biases. Thus, the RCF technique relies on a pool of past projects in order to form a reference class similar to the project under assessment. Flyvbjerg et al. (2003) investigated a set of reference classes depicting inaccuracies in the investment costs predictions. From these classes they developed a set of uplift values (in percentage) to be placed on the preliminary investment denoted as Optimism Bias uplifts (Flyvbjerg 2004).

Salling (2008) investigated a large pool of reference classes elaborated in Flyvbjerg et al. (2003) where two types of Probability Distribution Functions (PDFs)

Corresponding author: Kim Bang Salling

E-mail: kbs@transport.dtu.dk 
have been determined in terms of a Beta-PERT distribution for the overestimation of transport demand and an Erlang distribution for the underestimation of investment costs. Currently, Nicolaisen (2012) has collected and elaborated a new database comprising almost 200 transport infrastructure projects - the UNITE Project Database (UPD) containing the same information as presented in Flyvbjerg et al. (2003) with regard to bias in demand forecasts and construction costs. The two latter transport related impacts make up the key components in most transport evaluation schemes for which reason the remaining impacts within the CBA are considered 'certain' (Mackie et al. 2003). This paper, however, only investigates the overestimation of benefits in terms of applying PDFs whereas the underestimation of investment costs are assessed solely by the use of Optimism Bias uplifts as presented in Flyvbjerg (2004).

Reference Scenario Forecasting (RSF) is referred to as the combination of RCF and QRA brought together in a scenario-grid. The latter represents a set of exploratory scenarios relying on the case study to be investigated (Salling, Leleur 2012). The modeling frame will be operationalised by introducing a new version of a previously designed decision support model, CBA-DK (e.g. Salling 2008; Salling, Banister 2010), adopted for combining CBA and QRA, the UNITE-DSS (Uncertainties in Transport Project Evaluation - Decision Support System) model. The variation between scenarios will systematically be explored and related to the scenario-grid. The specific scenario input is assessed by making use of the triple estimation technique (Lichtenberg 2000) returning a minimum and maximum boundary corresponding to the shape of the Beta-PERT distribution. The RSF scenario grid of $3 \times 3$ encompasses a focal scenario 5 provided by the CBA together with Optimism Bias uplifts and QRA. The remaining 8 scenario inputs are determined based upon stakeholder and decisionmaker involvement. Hence, a final set of altogether nine scenarios is obtained. In addition to the actual RSF calculations the paper discusses its relevance as decision support for transport decision making with an explicit concern of project uncertainties and feasibility risk assessment.

This paper is disposed as follows. After this introduction a case description is made depicting the case study of connecting the Northern part of Zealand in Denmark (Elsinore) with the Southern Region of Sweden, Skane (Helsingborg). Subsequently the UNITE-DSS model is introduced together with preliminary results from a deterministic run within the model. A small section describes the use of the Optimism Bias uplifts that are applied on the investment costs of the case alternatives. Hereafter the methodological approach of reference class forecasting is explained with special emphasis on the demand forecasts which make up the travel time savings and ticket revenue effects included in the Cost Benefit Analysis. Then the Reference Scenario Forecasting approach is introduced with a set of exploratory scenarios. The stochastic result is presented in terms of certainty graphs and index values which function as risk-related decision support for the assessed transport infrastructure project. The final section gives a conclusion and a perspective on the further research.

\section{The Case Study: The HH Fixed Link Connection}

The Oresund Fixed Link connecting the greater area of Copenhagen with Malmo in Sweden opened in July 2000. Today, fourteen years after the opening, the railway line of the link is close to capacity resulting in delays and discomfort for the travellers. The case of this paper concerns a new complementary fixed link connection between Denmark and Sweden between the cities of Elsinore (Helsingor) and Helsingborg. Regionally, the proposed connection is expected to create a substantial increase in trade, education and work place related benefits. Ultimately it is expected that a fixed link with increased commuter traffic across the border will result in a common labour and residence market. In addition, the recent decision to construct the Femern Belt fixed link connecting Denmark with Germany will increase the number of travellers from central Europe through Denmark to the rest of Scandinavia (Sweden, Norway and Finland). This means further traffic to cross the Oresund (Larsen, Skougaard 2010).

The case is commonly referred to as the HH-Connection (Fig. 1) and has been examined since the 1980s where the first alignment proposals were suggested. The opening of the Oresund fixed link between Copenhagen and Malmo, however, postponed the $\mathrm{HH}$-Connection but now its implementation is recommenced as explained. In Fig. 1 the circle shows the proposed new fixed link located approximately $50 \mathrm{~km}$ north of the existing fixed link across Oresund.

The current situation with ferry service is referred to as the base scenario where two of the proposed alternatives will substitute the ferries with a fixed link (Alternatives 3 and 4 ) and two will keep the ferry operation (Alternatives 1 and 2), see Table 1.

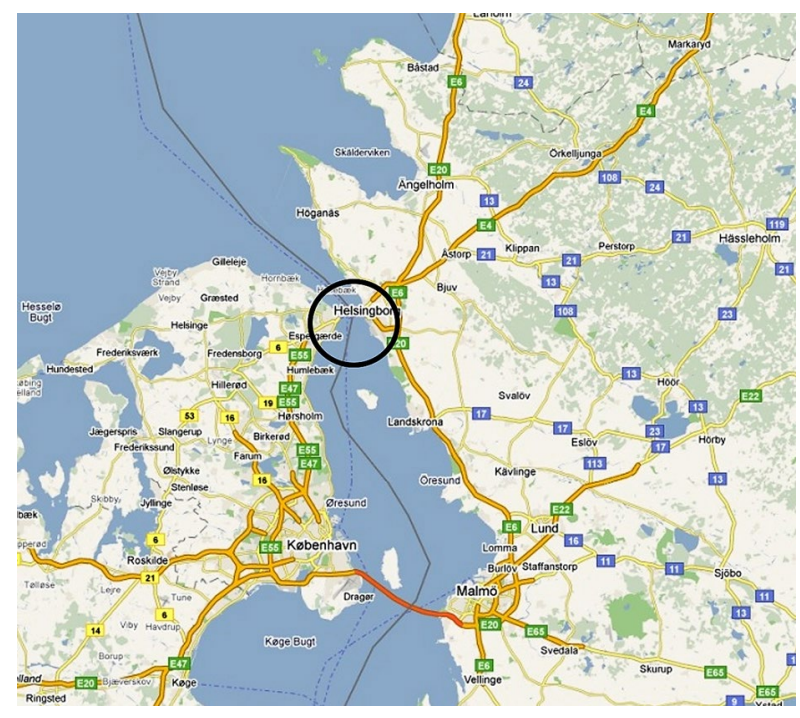

Fig. 1. The proposed new fixed link between Elsinore (Helsingor - Denmark) and Helsingborg (Sweden): the HH-Connection (from Google Maps) 
Table 1. The proposed four alternatives for the HH-Connection with construction costs in million DKK (adapted from Larsen, Skougaard 2010)

\begin{tabular}{|c|c|c|}
\hline HH-Connection & Description (alignment of connection) & Cost $[\mathrm{mDKK}]$ \\
\hline Alternative 1 & Tunnel for rail (2 tracks) person traffic only & 7700 \\
\hline Alternative 2 & Tunnel for rail (1 track) goods traffic only & 5500 \\
\hline Alternative 3 & Bridge for road and rail ( $2 \times 2$ lanes and 2 railway tracks $)$ & 11500 \\
\hline Alternative 4 & Bridge for road only $(2 \times 2$ lanes $)$ & 6000 \\
\hline
\end{tabular}

Note: $1 \mathrm{mDKK} \approx € 130000$.

The following section describes the UNITE-DSS model, made use of in order to assess the above four proposed alternatives in a socio-economic perspective. The model is composed of four modules (I-IV) where the first two comprise deterministic calculations in terms of cost-benefit analyses and Optimism Bias uplifts and the final two comprise stochastic calculations in terms of quantitative risk analyses respectively in terms of reference class forecasting and reference scenario forecasting.

\section{The UNITE-DSS Model}

The UNITE-DSS model is designed to bring informed decision support both in terms of single aggregated estimates such as the NPV and BCR but also in terms of interval results by accumulated probability curves (Salling 2008). The current interaction between the deterministic and stochastic part of the UNITE-DSS model aims to explore the feasibility risk highly relevant when assessing transport infrastructure projects. The software model is anchored on a Microsoft Excel platform with the CBA methodology following the Danish Manual for SocioEconomic Analysis (DMT 2003). Such type of analysis is often assigned with a substantial degree of uncertainties especially as concerns the investment costs of the transport project for which reason Optimism Bias uplifts have been applied within the modelling framework. The methodologies of CBA and Optimism Bias uplifts make up the deterministic procedure of the UNITE-DSS model.
The stochastic procedure of the model is based upon the @RISK software developed by Palisade Corporation as an add-in to Microsoft Excel (Palisade Corporation 2007). Even though the deterministic procedure introduces risks and uncertainties in terms of uplifts to the investment costs, another key impact within the CBA which is necessary to consider are the travel time savings (and ticket revenue). By applying RCF and QRA in terms of Monte Carlo simulation, this impact is explored in the modelling scheme in terms of PDFs.

Finally as part of the stochastic procedure a scenario forecasting module is applied in order to assess future-oriented trends such as economic development, levels of integration, etc. Currently, trend scenarios are defined in the UNITE-DSS model by varying the inputs from the travel time savings effect, i.e. increasing or decreasing the benefit stemming from the determined PDF (Lichtenberg 2000; Leleur et al. 2003; Salling, Leleur 2012). This methodological approach seen as an innovative feature of the model has been formulated as reference scenario forecasting since it builds upon the two concepts of RCF and scenario forecasting.

A flow chart of the UNITE-DSS model in its current version is depicted in Fig. 2. After each of the four module calculations, a result can be derived anchored within the CBA. The two stochastically based results are furthermore producing so-called certainty graphs and certainty values $(\mathrm{CVs})$ illuminating the socio-economic cut-off value with regard to feasibility, i.e. BCR $\geq 1.00$.

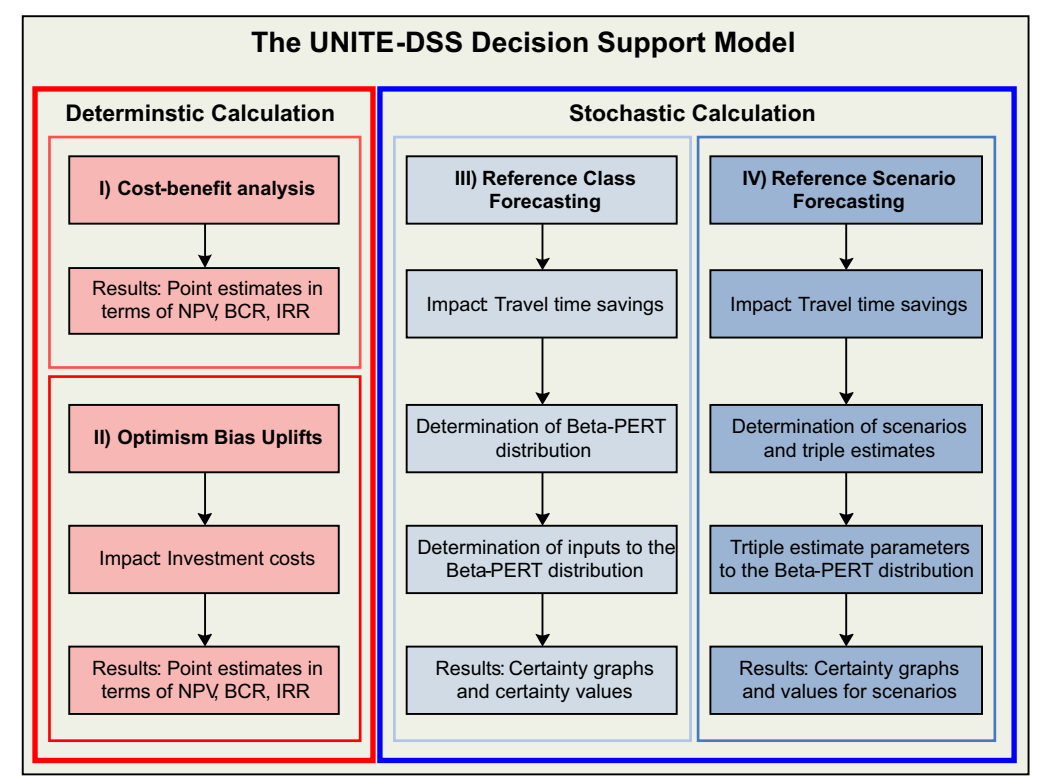

Fig. 2. Calculation procedure for the UNITE-DSS model for feasibility risk assessment 


\subsection{Cost-Benefit Analysis (Module I)}

Cost-benefit analysis seeks to determine whether or not a certain output shall be produced and, if so, how best to produce it. The method relies solely on the estimation of related impacts/effects of the project being examined and on validated unit prices made use of. The UNITE-DSS model applies a set of Danish unit prices and the guidelines formulated by the Danish Ministry of Transport (DMT 2003). Inputs to the CBA are shown in Table 2 consisting of construction costs (coast-to-coast construction), operating and maintenance, Travel Time Savings and Ticket Revenue (TTS-TR), Vehicle Operating Costs (VOC) and emissions where the substantial differences to the basis scenario are related to the ferry operations (note that $1 \mathrm{mDKK} \approx € 130000$ ).

Table 2 clearly depicts the influence from the two major components in any socio-economic analysis within transport infrastructure assessment, namely the construction costs and travel time savings including ticket revenue. The TTS-TR depicts the provision both in terms of the fixed link fee and the user benefits from the provision of the link. A third important impact is the emission in this case determined through air pollution (local and regional) and noise. Specifically, the two alternatives ( 3 and 4 ) with abandonment of ferry operations experience huge benefits. Accommodating such significant benefits from closing down the ferry operation is often debated, especially as the ferries become more and more environmentally friendly. The following model run is therefore only including growth in the first 20 year of the evaluation, where after it is constant.

Finally, the UNITE-DSS model initially produces a set of evaluation criteria in module I in terms of BCRs and NPVs, see Table 3.

The results in Table 3 depict three feasible project alternatives, i.e. alternatives 1,3 and 4 . The two bridge solutions clearly perform the best with high BCRs whereas alternative 2 with only one track for railway goods is performing poorly. Furthermore, for alternative 3 and 4 it should be noticed that with regard to the NPVs alternative 3 performs the best, while as concerns the BCRs alternative 4 performs the best.

\section{Reference Class Forecasting}

Traditionally transport infrastructure projects tend to be underestimated in terms of construction costs, deliberately or otherwise. Such underestimated costs for obvious reasons affect the overall assessment of the project in terms of its feasibility. Four categories of explanations for the underestimation of investment costs are given as technical, economic, political and psychological (Cantarelli et al. 2010; Mouter 2014). The technical explanation can be defined as forecasting errors rooted in imperfect techniques, inadequate data, honest mistakes, inherent problems in predicting the future and lack of experience. The economic explanation is rooted in terms of economic 'self-interest' or in terms of public interest resulting in deliberate underestimation of investment cost. Political explanations assume strategic misrepresentation when forecasting the outcomes of projects as the main reason for cost overruns also denoted as pessimism bias (Næss et al. 2006) and finally, the psychological explanations are rooted in planning fallacy and optimism bias (Flyvbjerg 2007). Osland, Strand (2010) makes a thorough discussion of estimation uncertainty and related factors of influence where an argument against strategic misrepresentation is put forward.

Below the methodology made use of in the UNITE-DSS model are presented through Optimism Bias and reference class forecasting.

The Optimism Bias approach is dealt with by the use of a well-established technique named RCF. The theoretical background to RCF originates in prospect theory developed by Kahneman and Tversky as part of a psychology study on human judgments (Kahneman, Tversky 1979). A reference class denotes a pool of past

Table 2. CBA impacts for the assessment of the HH-Connection project (adapted from Larsen, Skougaard 2010)

\begin{tabular}{lcccc}
\hline \multicolumn{1}{c}{ Impact } & Alternative 1 & Alternative 2 & Alternative 3 & Alternative 4 \\
\hline Construction costs [mDKK] & -7700 & -5500 & -11500 & -6000 \\
\hline Scrap value [mDKK] & 418 & 298.6 & 924.3 & 325.7 \\
\hline Operating and maintenance [mDKK/year] & -154 & -110 & -230 & -120 \\
\hline TTS-TR [mDKK/year] & 681.8 & 172.2 & 1374.9 & 1035.5 \\
\hline VOC [mDKK/year] & -32.3 & -12.4 & -89.3 & -50.8 \\
\hline Emission [mDKK/year] & 275.1 & -13.5 & 3345 & 3082 \\
\hline
\end{tabular}

Table 3. Results from the initial deterministic run of the UNITE-DSS model (based upon data material from Larsen, Skougaard 2010)

\begin{tabular}{lccc}
\hline \multicolumn{1}{c}{ HH-Connection } & Cost $[\mathrm{mDKK}]$ & BCR & NPV [mDKK] \\
\hline Alternative 1 & 7.7 & 1.15 & 1.8 \\
\hline Alternative 2 & 5.5 & 0.39 & -5.1 \\
\hline Alternative 3 & 11.5 & 2.17 & 20.3 \\
\hline Alternative 4 & 6.0 & 2.63 & 17.8 \\
\hline
\end{tabular}


projects similar to the one being appraised. A systematic collection of differences between forecast and actual values is gathered for a range of similar projects, the deficiencies in the forecast process (for costs and demand) are compared, and this evidence is then used to improve current decisions. Experience from past projects is then collected, compared and used so that 'planning fallacy' can be avoided (Buehler et al. 1994). Subsequently, the main area of interest is to collect and analyze a set of reference classes in order to facilitate the uncertainty (or bias) embedded within a transport related impact. The British Department for Transport issued a guidance report in 2004 elaborating upon the latter establishing so-called percentage uplifts to be applied on construction costs estimates before entered in a decision support model (Flyvbjerg 2004). Evidently, cost estimates (forecasted construction costs) for infrastructure projects are set against actual cost for the project via the following formula (Ibid.):

$$
U=\frac{\left(X_{a}-X_{f}\right) \cdot 100}{X_{f}},
$$

where: $U$ is percent inaccuracy; $X_{a}$ is the actual cost after the project is opened; $X_{f}$ is the forecasted or estimated cost.

Thus, the Optimism Bias uplifts should be applied to the estimated budget costs at the time of decision to build and they are referred to as the cost overruns calculated in fixed prices.

\subsection{Optimism Bias Uplifts (Module II)}

These deterministically derived Optimism Bias uplift values are implemented concerning the construction costs of the different alternatives for the HH-Connection within the UNITE-DSS model and a new set of evaluation criteria can be derived. Table 4 presents some of the uplifts applicable within transport infrastructure projects for different levels of certainty ranging from 50 90\% (Flyvbjerg 2004). The three main categories of road, rail and fixed link are covering a huge variety of different projects, i.e. road projects are for example divided into different reference classes comprising motorways, trunk roads, local roads, bus lane schemes etc. Rail projects have been divided into metro projects, light rail projects, high speed rail projects etc. whilst the fixed link category also covers bridges and tunnels.

Hence, if a group of decision-makers decides that the risk of a cost overrun must be less than $20 \%$ for a road type project, the construction cost estimate must be uplifted by $32 \%$. Thus, if the initial estimate was $100 \mathrm{mDKK}$ the final cost estimate taking into account the Optimism Bias at an $80 \%$ probability level would be $132 \mathrm{mDKK}$. The specified acceptance level corresponds to the decision-makers risk aversion of the project, i.e. it is assumed that the decision-makers allow a $20 \%$ threshold that the project will be exceeding its budget. Thus, module II produces a new set of BCRs for the project alternatives (Table 5) with $80 \%$ certainty as concerns cost estimate.

The results from module II of the UNITE-DSS model provide a sensitivity test based upon empirical evidence of past bias. The results show that even though the construction costs are being uplifted, the BCR values for the two alternatives 3 and 4 still indicate feasible socio-economic results. However, alternative 1, which previously returned a feasible result towards society now become infeasible with a $B C R=0.93$. Such shifts in feasibility are interesting from the decision-makers' point of view and will be a matter of concern further on.

Even though this method has proven useful in a number of cases in the British Department for Transport, the derived deterministic results are still given as point estimates i.e. in form of multiple single sensitivity tests on the construction cost. The second key impact to examine, see Table 2, is the travel time savings combined with the ticket revenue. Other recent studies have concluded that risk simulation can be assessed for construction cost uncertainties in terms of an Erlang distribution (Salling 2008; Salling, Banister 2009; Salling, Leleur 2012). This is, however, not given further attention in this paper.

The following sections propose a new methodological approach in order to achieve a more comprehensive assessment of the uncertainties embedded within transport infrastructure project appraisal. Specifically, mod-

Table 4. Optimism Bias uplifts (adapted from Flyvbjerg 2004)

\begin{tabular}{llllll}
\hline Level of acceptable optimism bias [\%] & 50 & 60 & 70 & 80 & 90 \\
\hline Road projects [\%] & 15 & 24 & 27 & 32 & 45 \\
\hline Rail (and air) projects [\%] & 40 & 45 & 51 & 57 & 68 \\
\hline Fixed links [\%] & 23 & 26 & 34 & 55 & 83 \\
\hline
\end{tabular}

Table 5. Results from a deterministic run of the UNITE-DSS model applying the Optimism Bias uplifts with $80 \%$ certainty

\begin{tabular}{lccc}
\hline HH-Connection (alternatives) & Cost (uplifted) $[\mathrm{mDKK}]$ & BCR (original) & BCR (55\% uplifted) \\
\hline Alternative 1 & 14.7 & 1.15 & 0.93 \\
\hline Alternative 2 & 10.5 & 0.39 & 0.33 \\
\hline Alternative 3 & 22.0 & 2.17 & 1.73 \\
\hline Alternative 4 & 11.5 & 2.63 & 2.10 \\
\hline
\end{tabular}


ules III and IV of the UNITE-DSS model make explicit use of a quantitative risk analysis and Monte Carlo simulation combined with reference class forecasting and scenario forecasting. The focus is on the inaccuracies in the forecasts of travel demand determining the effect of travel time savings and the ticket revenue.

\subsection{Demand Forecasts (Travel Time Savings and Ticket Revenue)}

By far the largest contributor of direct benefits from any given transportation project are the travel time savings and the ticket revenue for user paid infrastructure. Benefits originating from this category can make up a share in the range of $70-90 \%$ of the overall benefits (Mackie et al. 2003). These most influential benefits are based on demand forecasts that can determine the Travel Time Savings (TTS) and the Ticket Revenue (TR) (in the following abbreviated TTS-TR). Due to correlation between TTS and TR the UNITE-DSS model applies a single probability distribution to model the TTS-TR effect jointly.

A comparative study has investigated ex-ante based and ex-post based demand forecasts for rail and road infrastructure projects (Nicolaisen 2012; Ambrasaite et al. 2012). This study resulting in a database comprising almost 200 transport infrastructure projects (UPD Database), concluded that generally demand forecasts for road type projects with respect to the inaccuracy for traffic demand forecasts led to (in average) $22.3 \%$ higher traffic than predicted, cf. Fig. 3. For rail type projects demand forecast in average led to $13.5 \%$ lower traffic than predicted.

Moreover, for demand forecasts associated with fixed link projects such as tunnels or bridges led to $19.4 \%$ lesser traffic than anticipated. All three categories, however, have substantial standard deviations, as presented in Table 6 - note that a negative sign means overestimation of demand in the initial stage of the project (anticipation of traffic was higher than actual on the infrastructure).

The two modes of transport, road and rail, have been further investigated in Salling (2008) where data fits have been performed by the use of maximum likelihood estimators. In both cases it was suggested to use a Beta-PERT or triangular distribution to capture the skewness of the data i.e. the Beta-PERT distribution has been set as a default distribution to model inaccuracies depending on the demand forecasts (Salling, Leleur 2012).

The Beta-PERT distribution has a background as a useful tool for modelling expert data. Thus, PERT (Program Evaluation and Review Technique) originates from 1958 where it was assigned a so-called schedule procedure (Lichtenberg 2000; Vose 2008).
The Beta-PERT distribution is derived from the beta distribution, which mathematically is fairly simple and furthermore covers a huge variety of skewness types. When used in a Monte Carlo simulation, the Beta-PERT distribution can be used to specify risks in project and cost models especially based on the resemblance to the triangular distribution, see Fig. 4.

As with any probability distribution, the usefulness of this particular distribution is limited by the quality of the inputs: the better your expert estimates, the better results you can derive from a simulation. Thus, the unique database sample with minimum and maximum boundaries can be applied directly, as 'expert' entries to the Monte Carlo simulation. Moreover, the mean in the Beta-PERT distribution has four times the weighting on the mode (most likely value) compared with the triangular distribution. In real-life problems we are usually capable of giving a more confident guess of the mode rather than of the extreme values, hence the Beta-PERT distribution brings a much smoother description of the tales of the impacts to be considered (Lichtenberg 2000; Vose 2008).

As with the inaccuracy of cost estimates the inaccuracy of traffic forecasts is defined in the same manner, i.e. the actual traffic minus forecasted traffic in percentage of forecasted traffic. The actual traffic is furthermore

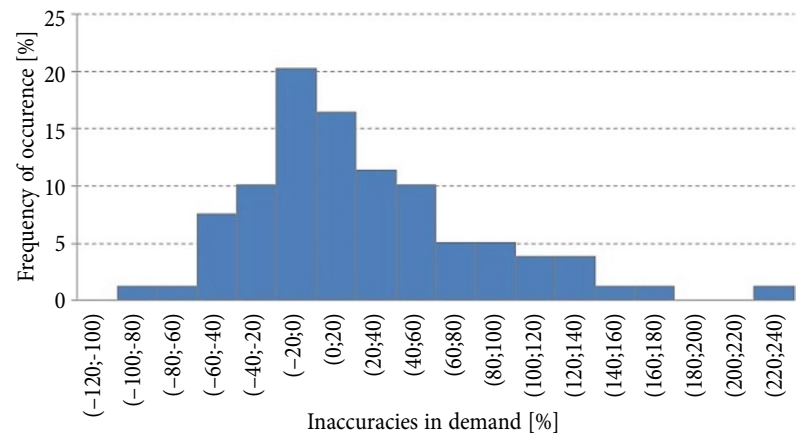

Fig. 3. Inaccuracies of demand forecasts for roads in 79 projects (inaccuracy is measured as actual minus forecast traffic in percentage of forecast traffic, thus, a negative sign refers to lower than actual)

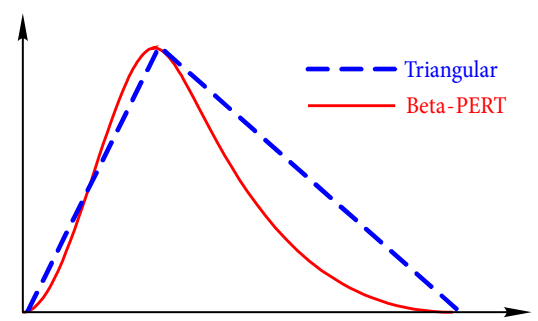

Fig. 4. Illustration of the PERT distribution compared with a triangular distribution with the same input parameters

Table 6. Results from a deterministic run of the UNITE-DSS model applying the Optimism Bias uplifts with 80\% certainty

\begin{tabular}{lcccccc}
\cline { 2 - 7 } & Rail & Road & Fixed link & Rail & Road & Fixed link \\
\cline { 2 - 7 } & $($ mean $)$ & $($ mean $)$ & $($ mean $)$ & $($ MIN/MAX) & $($ MIN/MAX) & $($ MIN/MAX) \\
\hline Traffic demand inaccuracy & $-13.5 \%$ & $22.3 \%$ & $-19.4 \%$ & {$[-76 \% ; 158 \%]$} & {$[-87 \% ; 229 \%]$} & {$[-82 \% ; 53 \%]$} \\
\hline
\end{tabular}


counted for the first year of operation (or the opening year) and the forecasted traffic demand is the estimate available to decision makers when they made the decision to build the project at question. One major issue when setting such point of reference is the disregarding of a ramp up - where most transport projects 'need' a couple of years to reach its total effect (Flyvbjerg et al. 2006). Moreover, it is important to realize how traffic forecasts are made. Most forecasts rely on traffic and demand models to decide how future traffic will grow as a consequence to the new project. However, projects are not all subjected to the same scrutiny as it comes to model development and implementation. Furthermore, some studies have revealed that political accepted goals merely have been translated into forecasted traffic (Næss, Strand 2012).

The UNITE-DSS model combines hereafter the uplifted construction costs shown in Table 5 with the estimated TTS-TR probability distribution functions. The interval results produced are depicted as certainty graphs i.e. accumulated descending graphs concerning the four alternatives, see Fig. 5. It has been assumed that the unit prices corresponding to the travel time savings are constant only following the growth in the net price index (DMT 2003; Salling 2008).

Unfortunately, RCF data with regard to the demand forecasts of fixed link projects is very scarce (only 15 projects are currently embedded within the database), thus, specifically as a UNITE-DSS model run alternative 1 and 2 (rail type projects) make use of the input parameters Beta-PERT $(-90 \% ;-37 \%$; 68\%) and alternative 4 (road type project) makes use of Beta-PERT $(-49 \%$; $10 \% ; 106 \%$ ), while alternative 3 (combined rail and road type projects) makes use of a combination between the

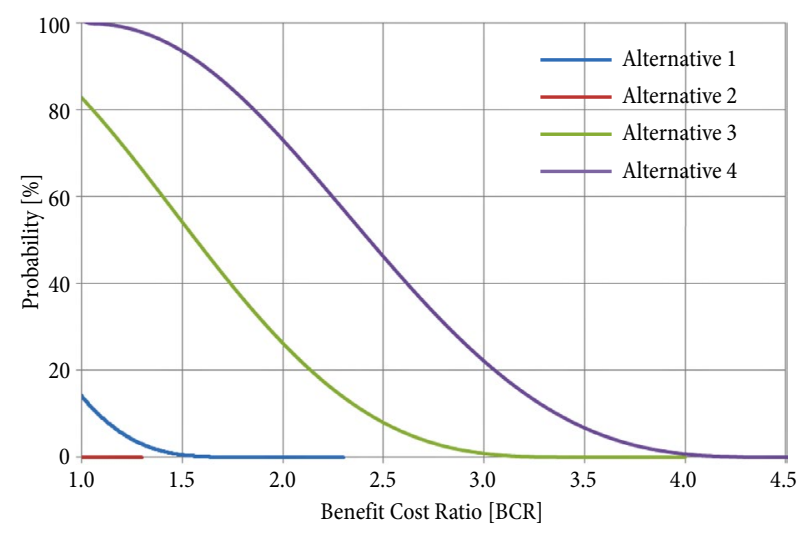

Fig. 5. Certainty graphs for the four alternatives in the $\mathrm{HH}$-Connection two, see Table 6. The simulation is performed in @RISK version 5.0 with 2000 iterations and a Latin Hypercube sampling method (Palisade Corporation 2007; Salling 2008).

The certainty graphs depicted in Fig. 5 show the feasibility of the different alternatives of the HH-Connection taking into account the inaccuracies in determining the demand forecasts (previously denoted feasibility risk assessment, see Salling (2008)). Please note, that alternative 2 does not become feasible in any of the Monte Carlo simulation iterations. The graphs show that the two bridge alternatives ( 3 and 4 ) perform the best, thus alternative 3 obtains a $\mathrm{CV}$ of $83 \%$ and alternative 4 obtains a CV $=100 \%$. The CV or index denotes the probability of achieving a BCR $\geq 1.00$. The tails of the output distributions illustrate the variance in terms of steepness, with steeper curves related to higher certainty and vice versa. Finally, Table 7 summarises the results in terms of the BCRs from module I and II and the CV of module III.

Table 7 shows that alternative 2 is not feasible seen from a societal point of view whereas alternative 1 seems to be feasible from a cost-benefit point of view; however, when assessing the uncertainties involved this alternative becomes 'infeasible', even though it produces feasible results in $14 \%$ of the simulation iterations. Alternative 3 and 4 perform overall the best with feasible results respectively in $83 \%$ and $100 \%$ of the simulations.

The final analysis is to perform a scenario analysis taking into account external factors in this case determined by the economic growth situation and the level of cross-border integration between Denmark and Sweden.

\section{Reference Scenario Forecasting}

Reference scenario forecasting is introduced as the combination of RCF and QRA brought together in a scenario-grid. Module IV of the UNITE-DSS model provides a final calculation procedure combining all three previous modules into one overall simulation. The scenarios in this study have been set up with respect to two main types of regimes: One regime which deals with the overall economic development (both nationally as well as internationally) and one regional/cross-border regime describing the future level of integration between the countries of Denmark and Sweden. The regimes vary in a $3 \times 3$ grid as depicted in Fig. 6 where the horizontal axis outlines the economic development and the vertical axis outlines the cross-border integration. Uncertainty tendencies as relating to the regimes have also been indicated in terms of arrows.

Table 7. Results from a stochastic run in the UNITE-DSS model applying the RCF-technique with respect to inaccuracies in demand forecasts

\begin{tabular}{lccc}
\hline HH-Connection (alternatives) & BCR (original) & BCR (uplifts) & CV [\%] (BCR $=1.00)$ \\
\hline Alternative 1 & 1.15 & 0.93 & 14 \\
\hline Alternative 2 & 0.39 & 0.33 & 0 \\
\hline Alternative 3 & 2.17 & 1.73 & 83 \\
\hline Alternative 4 & 2.63 & 2.10 & 100 \\
\hline
\end{tabular}




\begin{tabular}{|c|c|c|c|}
\hline & \multicolumn{3}{|c|}{ Economic development } \\
\hline & High & Middle & Low \\
\hline $\begin{array}{l}\text { Clearly } \\
\text { higher }\end{array}$ & Sc.1 & Sc. 4 & Sc.7 \\
\hline $\begin{array}{l}\text { Moderately } \\
\text { higher }\end{array}$ & Sc. 2 & Ref sc. 5 & Sc. 8 \\
\hline Current & Sc. 3 & Sc. 6 & Sc. 9 \\
\hline
\end{tabular}

Fig. 6. Scenario-grid for imagined futures for the HH-Connection project (adapted from Salling, Leleur 2012)

The nine scenarios that have been formulated are all expected to have different influences on the feasibility of the $\mathrm{HH}$-Connection project. The reference scenario 5 forms the basis as focal scenario for the RSF and the other 8 scenarios are set by assessing the development in expected travel time related benefits. In this context the focal scenario is based on the BCR calculations produced in module III and presented in Table 7. It has been assumed that in the actual case the construction cost effect is independent of the regimes, for which reason the Optimism Bias uplifts are considered 'certain'. The TTS-TR effect, however, will no doubt change as a consequence of the economic development and level of integration. Clearly, a high economic growth together with a high level of integration will mean more people that travel both as residents but particularly business, leisure and work-related trips will increase. The opposite tendency will turn out in the case of stagnation or financial crisis. All trips will then be at a minimum and the effect will decrease due to the lower number of trips across the $\mathrm{HH}$-Connection. The variation between scenarios is systematically explored and related to the scenario-grid (Fig. 6).

The specific scenario input concerning the BetaPERT distribution is assessed by combining empirical knowledge together with the triple estimation technique (Lichtenberg 2000). Larsen, Skougaard (2010) have elaborated upon the level of integration between Denmark and Sweden, where the level of integration following the current speed will reach 'full' integration in year 2049. Secondly, the economic growth affects the assessment study. The economic growth has been divided into a high, medium and low economic growth. It is furthermore assumed that the economic growth is correlated with the level of integration, thus, a high economic growth will lead to a high level of integration and vice versa.

Fig. 7 depicts the trends associated with the benefit stemming from the TTS-TR effect associated with each alternative and scenario. The vertical axis depicts the level of integration from a starting point at index 100 (in 2024) and increasing over time associated to the horizontal axis. The opening year is 2025 and the total evaluation period has been set to 50 years. Furthermore, the three types of economic growth scenarios have varying gradients in the first 25 years after which they are set to be constant (Larsen, Skougaard 2010). A benchmarking study in relation to the customized low, middle and

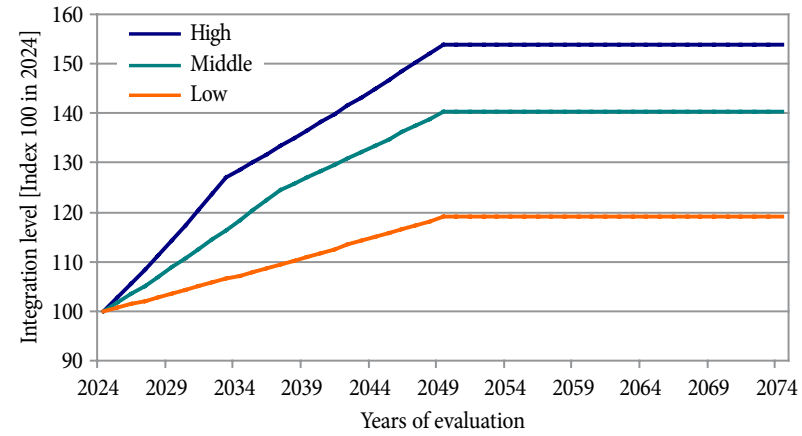

Fig. 7. Scenario trend development

(adapted from Annema et al. 2007; Larsen, Skougaard 2010)

high growth CBA introduced in the Netherlands similarly argues in order to appraise the risks and uncertainties embedded within transport CBA to allow such scenarios (Annema et al. 2007). Currently, no standardized scenario efforts have been made in Denmark, thus, the following sets of scenarios are determined based upon a forecasted economic growth situation combined with a level of integration between the Danish and the Swedish side (Larsen, Skougaard 2010).

The three trend graphs indicate possible futures with the high and low trend developments depicting upper and lower traffic forecast boundaries around a middle growth trend.

\subsection{Input to the Beta-PERT Distribution}

The main idea of RSF is based on assessing the Most Likely (ML), the maximum (MAX) and the minimum (MIN) values under the various scenario conditions. The scenario trend development graphs depicted in Fig. 7 are converted into percentage shares and applied respectively the most likely values concerning the TTS-TR impact for scenario 1 and 9, see Table 8. The two extreme scenarios are laying the foundation for the remaining set of scenarios.

Table 8 converts the empirical values derived from the scenario trend development graphs shown in Fig. 7. By assuming the focal scenario 5 to be the reference, the best future case for the TTS-TR effect is found in scenario 1 whereas the worst future case is found in scenario 9 . The remaining 6 scenarios, hence, are not further investigated due to the previous notion on correlation between economic growth and level of integration. If scenarios were formulated without such an assumption all nine scenarios must be formulated individually, see Salling, Leleur (2012).

The final step is to derive the minimum and maximum input parameters for the Beta-PERT distribution. The focal scenario 5 is based on the previous set of data fits from the RCF-technique, thus input parameters associated with the ML value can be derived as shown in Table 9. Secondly, the minimum and maximum input values are derived by the use of the reference classes determined within the UNITE Project Database (UPD). Thus, the triple values for the two final scenarios (SC1 and SC9) have been modified as related to data fitting respectively for rail projects (alternatives 1 and 2) for 
a combination of rail and road projects (alternative 3) and only road projects alternative 4 for the purpose to illustrate the approach of RSF. It should be noted that the MIN, ML and MAX for alternative 3 is divided to follow the data fit partly from rail and partly from road demand forecasts.

Evidently, the percentage changes to the ML value have been derived based on the performed data-fit which also displays relatively high standard deviations for the focal scenario 5. Moreover, these initial input parameters for the focal scenario are anchored in the following two scenarios. It is further assumed that the parameters in scenario 1 are assigned a high degree of uncertainty whereas scenario 9 has a relatively low degree of uncertainty, see Fig. 6. Thus, the following input parameters for the four alternatives have been derived as depicted in Tables 10 and 11 referring to the conversion of scenario trend development values displayed in Table 8.

Please note, that alternatives 1,2 and 3 in scenario 9 for the road TTS-TR comprise negative values. Evidently, this is not valid since a transport infrastructure project with negative user benefits would be rejected in the pre-analysis of the project. Thus, the lower boundary of the triple estimate has been rounded to 0 (Table 11).

A real-world application is currently under way in a decision conference framework where decision-makers and stakeholders will contribute to the minimum and maximum values (Goodwin, Wright 2004; Barfod 2012).

\subsection{Results from the Reference Scenario Forecasting}

Results from the final RSF risk simulation run in the UNITE-DSS model is shown in Table 12.

Table 8. Conversion of scenario trend development values

\begin{tabular}{lcc}
\cline { 2 - 3 } & Index value in 2074 & Most Likely (ML) [\%-conversion] \\
\hline Scenario 1 & 154 & SC 1 = 13.5\% \\
\hline Scenario 5 & 140 & Focal SC 5 = 0 \\
\hline Scenario 9 & 119 & SC 9 $=-21.2 \%$ \\
\hline
\end{tabular}

Table 9. Focal scenario 5 TTS-TR parameters to the PERT distribution [mDKK]

\begin{tabular}{lccc} 
& MIN SC 5 & ML SC 5 & MAX SC 5 \\
\hline Alternative 1 & $1270(-90 \%)$ & $8002(-37 \%)$ & $21340(68 \%)$ \\
\hline Alternative 2 & $452(-90 \%)$ & $2850(-37 \%)$ & $7599(68 \%)$ \\
\hline \multirow{2}{*}{ Alternative 3 } & $2654(-90 \%)$ & $16722(-37 \%)$ & $44592(68 \%)$ \\
\hline Alternative 4 & $3017(-49 \%)$ & $6507(10 \%)$ & $12186(106 \%)$ \\
\hline
\end{tabular}

Table 10. Scenario 1 TTS-TR parameters to the Beta-PERT distribution [mDKK]

\begin{tabular}{lccc} 
& MIN SC 1 & ML SC 1 & MAX SC 1 \\
\cline { 2 - 4 } Alternative 1 & $1270(-90 \%)$ & $14421(13.5 \%)$ & $27691(118 \%)$ \\
\hline Alternative 2 & $452(-90 \%)$ & $5135(13.5 \%)$ & $9861(118 \%)$ \\
\hline \multirow{2}{*}{ Alternative 3 } & $1898(-90 \%)$ & $18985(13.5 \%)$ & $41386(118 \%)$ \\
\hline Alternative 4 & $3767(-49 \%)$ & $7387(13.5 \%)$ & $18912(118 \%)$ \\
\hline
\end{tabular}

Table 11. Scenario 9 TTS-TR parameters to the Beta-PERT distribution [mDKK]

\begin{tabular}{lccc} 
& MIN SC 9 & ML SC 9 & MAX SC 9 \\
\hline Alternative 1 & $-5081 \approx 0(-140 \%)$ & $10004(-21 \%)$ & $14989(18 \%)$ \\
\hline Alternative 2 & $-1809 \approx 0(-140 \%)$ & $3563(-21 \%)$ & $5338(18 \%)$ \\
\hline \multirow{2}{*}{ Alternative 3 } & $-5268 \approx 0(-140 \%)$ & $13170(-21 \%)$ & $15541(18 \%)$ \\
\hline Alternative 4 & $51(-99 \%)$ & $5125(-21 \%)$ & $8506(66 \%)$ \\
\hline
\end{tabular}

Table 12. Certainty value results from the reference scenario forecasting

\begin{tabular}{lccc}
\hline $\begin{array}{c}\text { HH-Connection } \\
\text { (Alternative) }\end{array}$ & $\begin{array}{c}\text { CV [\%] } \\
\text { Scenario 1 }\end{array}$ & $\begin{array}{c}\text { CV [\%] } \\
\text { Scenario 5 }\end{array}$ & $\begin{array}{c}\text { CV [\%] } \\
\text { Scenario 9 }\end{array}$ \\
\hline Alternative 1 & $57 \%$ & $14 \%$ & $5 \%$ \\
\hline Alternative 2 & $0 \%$ & $0 \%$ & $0 \%$ \\
\hline Alternative 3 & $93 \%$ & $83 \%$ & $66 \%$ \\
\hline Alternative 4 & $100 \%$ & $100 \%$ & $80 \%$ \\
\hline
\end{tabular}


The values indicate the certainty (probability) of achieving the threshold value $(\mathrm{BCR}=1.00)$ denoted on the $y$-axis of the certainty graph, see Fig. 8. From Table 12 it is clear that alternative 4 performs overall the best, where, the most pessimistic scenario still returns an $80 \%$-feasibility of the project. Moreover, alternative 2 should be rejected since none of the scenarios returns a feasible result. The certainty graphs from module IV of the UNITE-DSS model are shown in Fig. 8.

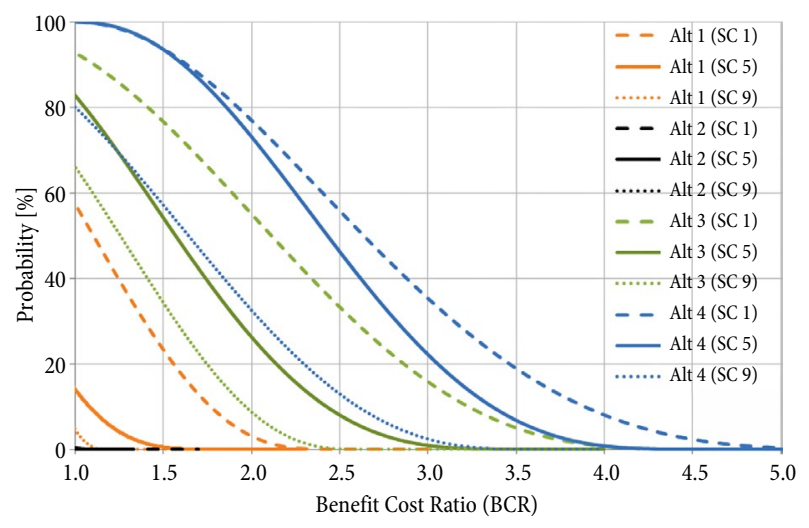

Fig. 8. Certainty graphs from the reference scenario forecasting run

Characteristically, the certainty graphs are downward sloping illustrating the uncertainty of the alternative within the scenario. The risk aversion is shown on the $y$-axis where the level of certainty is displayed. Thus, decision-makers with no risk aversion would only allow alternative 4 with respect to scenario 1 and 5 to be selected. However, lesser risk aversive decision-makers would be expected to allow for 70 or $60 \%$ certainty of feasibility. If this were the case, alternative 3 in all scenarios would also be of relevance. The strength of such analysis is clearly to avoid bias and strategic misrepresentation in the pre-stage of a project analysis - if you will - a worst case/best case analysis of the project.

\section{Discussion}

From the analyses carried out in this paper for the four $\mathrm{HH}$-Connection alternatives alternative 4 performs overall the best. Whether this project alternative should call for implementation, however, is a different issue? Especially, the main difference between the two alternatives 3 and 4 concerning travel modes must be considered before the final choice and unavoidably the huge difference in investment costs.

Furthermore, the RSF approach considered in this paper only relies upon the cost-benefit approach comprising monetary quantifiable impacts. However, nonquantifiable impacts such as landscape, ecology, regional economic development, transport network and accessibility, etc., have not been treated (Lootsma 1992; Barfod et al. 2011; Leleur 2012). Moreover, as put forward from Fig. 6 and the following tables of results from the RSF approach - benefits including revenue from international travellers contribute to the TTS-TR effect. Evidently, the demand side for the fixed link contributing to such high travel time savings and ticket revenue has not been tested within this paper. Further control and modelling are needed in order to captivate the rebound effect as well as the system effect on the overall transportation network.

Finally, the off-set from the constructed set of nine scenarios within the RSF method are based upon the focal reference scenario 5 in the middle of Fig. 6 . This should by nature be dynamic, thus, changing depending on the current economic development and level of integration. The procedure outlined presently is for the sake of illustration set in the middle i.e. the TTS-TR calculations are based upon this reference scenario. Future assessment and determination of a reference scenario are clearly needed as the remaining set of input distributions heavily relies upon the latter.

\section{Conclusions}

The paper has presented a new methodological approach, reference scenario forecasting, to explore embedded uncertainties in transport project assessment. Reference Scenario Forecasting (RSF) combines Reference Class Forecasting (RCF) and quantitative risk analysis with scenario forecasting, where the different scenarios are specified in an operational way by using triple estimates. A major strength of this technique is that overall feasibility risk assessment can be carried out by using historical experience stemming from RCF and by linking this to formulated scenarios of relevance for a particular case study.

The RSF approach has been illustrated on a case example concerning the construction of a new fixed link, the HH-Connection, between Denmark and Sweden. It has been demonstrated that RSF has a capability of providing informed decision support for a complex problem in a straightforward way based upon risk simulation and scenarios. The introduction of a set of triple estimates assigned the travel time savings effect comprises assessment information based upon judging the embedded risks of the project. Hereby, decision-makers are able to view and appraise their preferences towards an alternative in terms of feasibility risk assessment. A future task is to clarify and validate the inputs to the probability distribution functions drawing upon stakeholder and decision-maker involvement. One issue to further investigate would be to apply a decision conference for this purpose. Another issue is clearly to seek out and embed distributional inputs to the construction cost as well - since the major difference between the two best performing alternatives are the investment costs.

The inclusion of trend scenarios within transport assessment schemes as proposed herein allows decision makers to get a broader vision of the complex task of assessing infrastructure projects. The necessity for including scenarios in combination with economic analyses bridges the current implementation gap between on the one hand side massive data and research reports of inaccuracies and uncertainties for transport project in- 
vestments and on the other hand decision support tools and systems.

An important aspect in RSF is to set and validate input parameters. Hence, empirical data enter the assessment in terms of RCF and Optimism Bias uplifts. However, care must be taken in applying such data as they are based upon historical e.g. past trends and state of the market. In fact, recent discussions 'attack' the traditional transport economical thinking concerning the conceptual understanding of travel time savings. Metz (2008) initiated a large-scale discussion arguing that no empirical evidence are present supporting that travel time savings in fact are the main benefit in transport appraisal. Clearly, the inputs to the UNITE-DSS model specifically as regard the TTS-TR effect are of vital importance to produce reliable scenario forecasts. Thus, an important task is to supplement the set of reference classes with plausible trend scenarios that can represent new possible developments.

The RSF approach has been implemented in a decision support software model, UNITE-DSS. The approach relies on clearly defined and debated scenarios where a future task will be to develop a set of guidelines, i.e. short-list containing widely-embracing scenarios such as oil prices, evolution of the energy market and environmental initiatives could be of interest. This software carries the assessment study forward in different modules (I-IV) all anchored in monetary quantifiable measures. These modules rely on well-explored methodologies: cost-benefit analysis, Monte Carlo simulation and RCF. Future tasks are to develop the UNITE-DSS model to be informed by decision conferences. This linkage of modelling and decision-makers is seen as highly important to explore and assess the full potential of RSF. The issues of risk and uncertainty should be central in all types of project analysis as substantial sums of capital are transferred to transport infrastructure projects. Better and more comprehensive approaches towards transport assessment for decision making are therefore essential.

\section{References}

Ambrasaite, I.; Nicolaisen, M. S.; Leleur, S.; Salling, K. B. 2012. UPD - the UNITE Project Database: Collection of Reference Class Information: Database Concerning Cost and Demand Inaccuracies. Database developed as part of the UNITE (Uncertainties in Transport Project Evaluation) project funded by the Danish Council for Strategic Research (2009-2013).

Annema, J. A.; Koopmans, C.; Van Wee, B. 2007. Evaluating transport infrastructure investments: the dutch experience with a standardized approach, Transport Reviews 27(2): 125-150. http://dx.doi.org/10.1080/01441640600843237

Barfod, M. B. 2012. An MCDA approach for the selection of bike projects based on structuring and appraising activities, European Journal of Operational Research 218(3): 810-818. http://dx.doi.org/10.1016/j.ejor.2011.11.038

Barfod, M. B.; Salling, K. B.; Leleur, S. 2011. Composite decision support by combining cost-benefit and multi-criteria decision analysis, Decision Support Systems 51(1): 167-175. http://dx.doi.org/10.1016/j.dss.2010.12.005
Buehler, R.; Griffin, D.; Ross, M. 1994. Exploring the "planning fallacy": why people underestimate their task completion times, Journal of Personality and Social Psychology 67(3): 366-381. http://dx.doi.org/10.1037/0022-3514.67.3.366

Cantarelli, C. C.; Flyvbjerg, B.; Molin, E. J. E.; Van Wee, B. 2010. Cost overruns in large-scale transportation infrastructure projects: explanations and their theoretical embeddedness, European Journal of Transport Infrastructure Research 10(1): 5-18.

DMT. 2003. Manual for Socio-Economic Analysis - Applied Methodology in the Transport Sector. Guidance Document prepared for the Danish Ministry of Transport (DMT). 118 p. (in Danish).

Flyvbjerg, B. 2007. Megaproject Policy and Planning: Problems, Causes, Cures: Summary of Doctoral Dissertation (Dr Habil). Aalborg University. 61 p. Available from Internet: http://flyvbjerg.plan.aau.dk/Publications2007/afhandlingBF2007s.pdf

Flyvbjerg, B. 2004. Procedures for Dealing with Optimism Bias in Transport Planning. Guidance Document. The British Department for Transport. 61 p. Available from Internet: http://flyvbjerg.plan.aau.dk/0406DfT-UK\%20OptBiasASPUBL.pdf

Flyvbjerg, B.; Skamris Holm, M. K.; Buhl, S. L. 2006. Inaccuracy in traffic forecasts, Transport Reviews 26(1): 1-24. http://dx.doi.org/10.1080/01441640500124779

Flyvbjerg, B.; Skamris Holm, M. K.; Buhl, S. L. 2003. How common and how large are cost overruns in transport infrastructure projects?, Transport Reviews 23(1): 71-88. http://dx.doi.org/10.1080/01441640309904

Goodwin, P.; Wright, G. 2004. Decision Analysis for Management Judgment. 3rd edition. Wiley. 477 p.

Kahneman, D.; Tversky, A. 1979. Prospect theory: an analysis of decision under risk, Econometrica 47(2): 263-292. http://dx.doi.org/10.2307/1914185

Larsen, L. A.; Skougaard, B. Z. 2010. Appraisal of Alternatives Concerning a Fixed Link Between Elsinore and Helsingborg: MSc Thesis. Technical University of Denmark. 138 p. (in Danish).

Leleur, S. 2012. Complex Strategic Choices: Applying Systemic Planning for Strategic Decision Making. Springer. $170 \mathrm{p}$.

Leleur, S.; Holvad, T.; Salling, K. B.; Jensen, A. V. 2003. Development of the CLG-DSS Evaluation Model: Midterm Report presenting the CTT Contribution to Task 9. Centre for Logistics and Goods Transport (CLG), Technical University of Denmark. 206 p.

Lichtenberg, S. 2000. Proactive Management of Uncertainty Using the Successive Principle: a Practical Way to Manage Opportunities and Risks. Polyteknisk Forlag. 334 p.

Lootsma, F. A. 1992. The REMBRANDT System for Multi-Criteria Decision Analysis via Pair Wise Comparisons or Direct Weighting. Report 92-05. Delft University of Technology.

Mackie, P.; Preston, J. 1998. Twenty-one sources of error and bias in transport project appraisal, Transport Policy 5(1): 1-7. http://dx.doi.org/10.1016/S0967-070X(98)00004-3

Mackie, P. J.; Wardman, M.; Fowkes, A. S.; Whelan, G.; Nellthorp, J.; Bates, J. 2003. Value of Travel Time Savings in the UK: Summary Report. University of Leeds and John Bates Services. 18 p. Available from Internet: http://www.its. leeds.ac.uk/downloads/VOTSummary.pdf

Mouter, N. 2014. Cost-Benefit Analysis in Practice: a Study of the Way Cost-Benefit Analysis is Perceived by Key Individuals in the Dutch CBA Practice for Spatial-Infrastructure 
Projects: PhD Dissertation. TRAIL Research School, The Netherlands. $216 \mathrm{p}$.

Metz, D. 2008. The myth of travel time saving, Transport Reviews 28(3): 321-336. http://dx.doi.org/10.1080/01441640701642348

Nicolaisen, M. S. 2012. Forecasts: Fact or Fiction? Uncertainty and Inaccuracy in Transport Project Evaluation: PhD Thesis. Aalborg University. 226 p. Available from Internet: http:// vbn.aau.dk/files/81035038/Nicolaisen_2012_Forecasts_ Fact_or_Fiction_PhD_Thesis.pdf

Næss, P.; Flyvbjerg, B.; Buhl, S. 2006. Do road planners produce more 'honest numbers' than rail planners? An analysis of accuracy in road-traffic forecasts in cities versus peripheral regions, Transport Reviews 26(5): 537-555. http://dx.doi.org/10.1080/01441640500532005

Næss, P.; Nicolaisen, M. S.; Strand, A. 2012. Traffic forecasts ignoring induced demand: a shaky fundament for costbenefit Analyses, European Journal of Infrastructure Research 12(3): 291-309.

Næss, P.; Strand, A. 2012. What kinds of traffic forecasts are possible?, Journal of Critical Realism 11(3): 277-295. http://dx.doi.org/10.1558/jcr.v11i3.277

Odeck, J. 2010. What determines decision-makers' preferences for road investments? Evidence from the Norwegian road sector, Transport Reviews 30(4): 473-494. http://dx.doi.org/10.1080/01441640903138640

Osland, O.; Strand, A. 2010. The politics and institutions of project approval - a critical-constructive comment on the theory of strategic misrepresentation, European Journal of Transport Infrastructure Research 10(1): 77-88.

Palisade Corporation. 2007. @RISK - Risk Analysis and Simulation Add-In for Microsoft Excel. Version 5.0. User Guide. New York. 652 p.

Salling, K. B. 2008. Assessment of Transport Projects: Risk Analysis and Decision Support: PhD Thesis. Technical University of Denmark. 242 p. Available from Internet: http://orbit.dtu.dk/fedora/objects/orbit:82482/datastreams/ file_4980374/content

Salling, K. B.; Banister, D. 2010. Feasibility risk assessment of transport infrastructure projects: the CBA-DK decision support model, European Journal of Transport Infrastructure Research 10(1): 103-120.

Salling, K. B.; Banister, D. 2009. Assessment of large transport infrastructure projects: The CBA-DK model, Transportation Research Part A: Policy and Practice 43(9-10): 800813. http://dx.doi.org/10.1016/j.tra.2009.08.001

Salling, K. B.; Leleur, S. 2012. Modelling of transport project uncertainties: feasibility risk assessment and scenario analysis, European Journal of Infrastructure Research 12(1): 21-38.

Salling, K. B.; Leleur, S. 2011. Transport appraisal and Monte Carlo simulation by use of the CBA-DK model, Transport Policy 18(1): 236-245.

http://dx.doi.org/10.1016/j.tranpol.2010.08.007

Vose, D. 2008. Risk Analysis: a Quantitative Guide. 3rd edition. Wiley. 752 p.

Welde, M.; Odeck, J. 2011. Do planners get it right? The accuracy of travel demand forecasting in Norway, European Journal of Transport and Infrastructure Research 11(1): 80-95. 